\title{
A CASE REPORT OF AN INNOVATIVE TECHNIQUE FOR REMOVING FOREIGN BODY (MARBLE) FROM THE OESOPHAGUS
}

Shaila Sidam¹, V.P. Narve'2, Kavish Jhawar ${ }^{3}$

\section{HOW TO CITE THIS ARTICLE:}

Shaila Sidam, VP Narve, Kavish Jhawar. "A case report of an innovative technique for removing foreign body (marble) from the oesophagus". Journal of Evolution of Medical and Dental Sciences 2013; Vol2, Issue 37, September 16; Page: 7084-7085.

ABSTRACT: Oesophageal foreign bodies are commonly removed with rigid oesophagoscope under GA, but spherical foreign bodies are difficult to grasp hence difficult to remove. We report a case of $7 y r$ old male who had ingested foreign body (marble) in oesophagus and whose removal was done by an innovative technique.

KEYWORDS: foreign body, marble, Oesophagus, Spherical

INTRODUCTION: One of the most common ENT emergencies is foreign body ingestion and they are usually removed using rigid oesophagoscope under GA, but certain foreign bodies which are spherical are difficult to grasp and to remove. Various alternative methods have been used for extracting smooth objects like Magill's forceps, Foley's catheter, oesophageal boungienage, and surgery. In this report we describe successful removal of spherical foreign body from oesophagus using an innovative technique. ${ }^{1}$

CASE REPORT: A 7yr old male presented to ENT emergency of GRMC, Gwalior with the complaints of accidental ingestion of foreign body(marble)since few hours .He had complaints of dysphagia but no respiratory distress. X-ray soft tissue neck and upper chest AP view revealed a spherical foreign body of $1 \mathrm{~cm}$ in diameter at the mid oesophageal level. Rigid oesophagoscopy was performed and conventional foreign body catcher was used but as there was no space between the foreign body and the oesophageal wall so it was not possible to remove it and to push it further down. A laparoscopic tooth forceps was introduced with its closed prongs through the oesophagoscope and on reaching the marble the prongs were opened and the foreign body was grasped and the laparoscopic forceps along with the oesopagoscope were pulled out and foreign body was removed.

The child was asymptomatic and discharged from the hospital the next day.
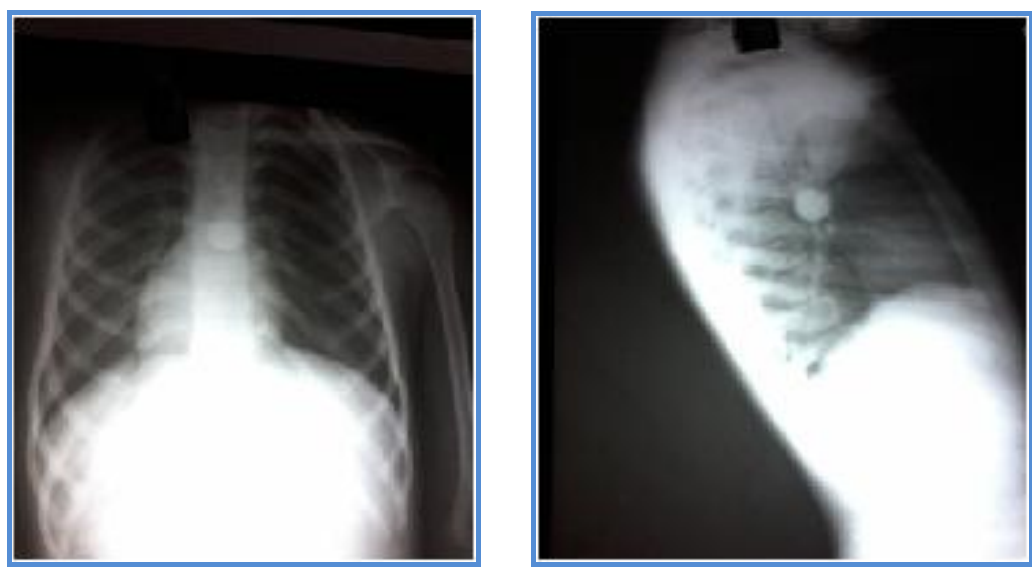

X-ray chest showing radio opaque circular foreign body 

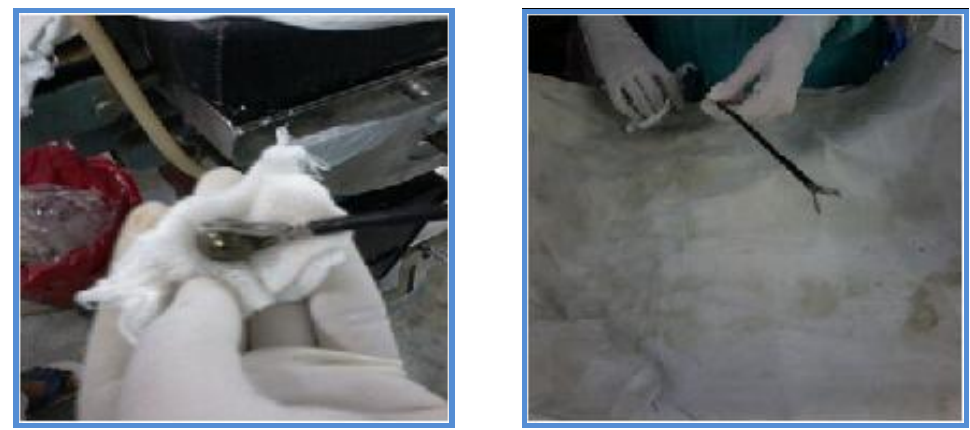

Foreign body removal forceps

DISCUSSION: Foreign body coin is the most common foreign body emergencies in ENT, but spherical foreign body like marble are a challenge to remove because of its shape, it becomes difficult to grasp using conventional foreign body removing forceps. They require different technique and instruments for removal. ${ }^{1}$ Foley's catheter method of removing the spherical foreign body has gradually increased but in our case as there was no space between the foreign body and the wall of oesophagus so it was of no use as it could not be passed. Timely use of an innovative practice of using laparoscopic forceps, we were successfully able to remove the foreign body. ${ }^{2}$

CONCLUSION: A technique of using laparoscopic forceps to remove marble oesophageal foreign body is described and this technique can be one of the many techniques u1sed by ENT surgeons to remove spherical foreign bodies from the oesophagus.

\section{REFERENCES:}

1. R.K.Shukla, Anirudh Shukla, Akshay Shivappa, Rinki Jain An innovative technique for removing a foreign body (glass marble) from esophagus www.waent.org March 13,2010

2. 2.R.D.Pathak, Vinay Gupta, S.S. Dubey An Unusual technique for removal of occult foreign body (glass marble) lying in mid oesophagus for 1 year Indian journal of otolaryngology and head and neck surgery, vol 52,issue 4,oct-dec2000

\section{AUTHORS:}

1. Shaila Sidam

2. V.P. Narve

3. Kavish Jhawar

\section{PARTICULARS OF CONTRIBUTORS:}

1. Assistant Professor, Department of Otorhinolaryngology, Gajra Raja Medical College, Gwalior, (M.P.)

2. Associate Professor and HOD, Department of Otorhinolaryngology, Gajra Raja Medical College, Gwalior, (M.P.)

3. PG Student, Department of Otorhinolaryngology, Gajra Raja Medical College, Gwalior, (M.P.)

\section{NAME ADDRESS EMAIL ID OF THE CORRESPONDING AUTHOR: \\ Dr. Shaila Sidam, Assistant Professor, Department of ENT, G.R.M.C., Gwalior \& JAH (M.P.) -474009. \\ Email-gujulsidam@yahoo.co.in}

Date of Submission: 05/09/2013. Date of Peer Review: 06/09/2013. Date of Acceptance: 06/09/2013. Date of Publishing: 11/09/2013 